\title{
Descriptive and Substantive Representation in Congress: Evidence from 80,000 Congressional Inquiries 110
}

\author{
Kenneth Lowande University of Michigan \\ Melinda Ritchie University of California, Riverside \\ Erinn Lauterbach University of California, Riverside
}

\begin{abstract}
A vast literature debates the efficacy of descriptive representation in legislatures. Though studies argue it influences how communities are represented through constituency service, they are limited since legislators' service activities are unobserved. Using Freedom of Information Act (FOIA) requests, we collected 88,000 records of communication between members of the U.S. Congress and federal agencies during the 108th-113th Congresses. These legislative interventions allow us to examine members' "follow-through" with policy implementation. We find that women, racial/ethnic minorities, and veterans are more likely to work on behalf of constituents with whom they share identities. Including veterans offers leverage in understanding the role of political cleavages and shared experiences. Our findings suggest that shared experiences operate as a critical mechanism for representation, that a lack of political consensus is not necessary for substantive representation, and that the causal relationships identified by experimental work have observable implications in the daily work of Congress.
\end{abstract}

Replication Materials: The data and materials required to verify the computational reproducibility of the results, procedures and analyses in this article are available on the American Journal of Political Science Dataverse within the Harvard Dataverse Network, at: https://doi.org/10.7910/DVN/VJLVYU.

W ell-intentioned laws may exacerbate political inequality if implemented in ways that fail to aid the citizens they are intended to protect. Yet, studies of representation focus on how constituents are represented through the creation of law, overlooking its execution. Accounts of federal agencies' stalled implementation of the Civil Rights Act, mismanagement of workplace rights violations, and falsification of veterans' health care records demonstrate how cracks in the ideals of democratic representation can spread through policy implementation - precariously beyond the public purview. Demands made by elected officials are an important means of remedy.

Scholars know little about how descriptive representation impacts legislative interventions with agencies on behalf of protected groups. This overlooked venue of representation is particularly important given the extensive role of federal agencies in policymaking and a history of agencies' neglecting groups of citizens they were entrusted to protect (Minta 2009, 2011). We shed light on this phenomenon by examining whether members of Congress advocate on behalf of protected classes of citizens by communicating directly with the federal bureaucracy.

This analysis is the first of its kind, possible only by obtaining and constructing a unique data set of over 88,000 congressional contacts assembled from a series of Freedom of Information Act (FOIA) requests. These data allow us to consider whether descriptively representative members of Congress (e.g., racial and ethnic minorities, women, and veterans) advocate for underrepresented communities by intervening with federal agencies

Kenneth Lowande is Assistant Professor, Department of Political Science, University of Michigan, 6658 Haven Hall, 505 South State Street, Ann Arbor, MI 48109 (lowande@umich.edu). Melinda Ritchie is Assistant Professor, Department of Political Science, University of California, Riverside, 900 University Avenue, Riverside, CA 92521 (melinda.ritchie@ucr.edu). Erinn Lauterbach is Ph.D. Candidate, Department of Political Science, University of California, Riverside, 900 University Avenue, Riverside, CA 92521 (elaut001@ucr.edu).

A previous version of this article was presented at the 2017 annual meeting of the Midwest Political Science Association, Chicago. We thank Ben Bishin, Daniel Butler, Jason Coronel, Jason MacDonald, Jennifer Merolla, Ben Newman, and Sono Shah for helpful comments and suggestions. Special thanks to CW5 Jeffrey Freelove, USA, Ret.

American Journal of Political Science, Vol. 63, No. 3, July 2019, Pp. 644-659

(C)2019, Midwest Political Science Association

DOI: 10.1111/ajps.12443 
implementing law. Do representatives follow up on the policy interests of women, minorities, and veterans long after a bill's passage? Do they monitor agencies to ensure the rights of these communities are protected?

By shedding light on these questions, records of legislative interventions in the bureaucracy offer a unique approach to the study of representation. Unlike voting records, bill sponsorship, speeches, and committee hearings - which are influenced by both internal and external institutional pressures-representatives are comparatively less constrained in their communications with the federal bureaucracy (Grose 2011). Moreover, we build on novel experimental work that investigates legislators' responsiveness to constituents based on shared race and gender (Butler 2014; Butler and Broockman 2011). By analyzing interventions in the bureaucracy, we assess whether the underlying causal relationships identified by these studies on state legislators have observable, systematic implications in the U.S. Congress. Put differently, our analysis assesses the quality of legislative "followthrough" on behalf of these constituents-rather than direct responses to the constituents themselves.

We find significant differences in the intervention patterns of female, minority, and veteran legislators that suggest descriptive representation leads to substantive representation in Congress. In each case, we find that in a given Congress, legislators are around 6-9 percentage points more likely to contact federal agencies on behalf of constituents with whom they share background characteristics, when compared to their nonveteran, male, or white colleagues. The differences are most striking for women and men in Congress, where being represented by a female legislator is associated with a $40 \%$ increase in the probability of relevant service. These differences are robust after accounting for factors influencing the selection of legislators, are consistent across multiple measures of representation, and remain when limiting the analysis to split-representation delegations in the U.S. Senate-a context that holds legislative district constant.

This approach advances existing work on descriptive representation and has important implications for future research. First, existing observational work focusing on legislative activity must consider numerous crosscutting influences on legislative behavior. For example, raceor gender-related legislation can be censored (e.g., via committees and party agenda setting) before minority and women legislators register their votes. In contrast, our data demonstrate comparatively "unilateral" action on the part of legislators-not subject to chamber rules, logrolling, and negative agenda control. This limits the number of potential explanations for observed patterns. Second, our approach offers a unique opportunity to test the implications of existing experimental work. Our analysis is descriptive and not intended to adjudicate between alternative causal pathways of substantive representation-such as strategic prioritization, personal bias, or constituent behavior. Nonetheless, existing studies investigate these mechanisms, and each implies a similar relationship between descriptive and substantive representation. This study evaluates whether one or more of these mechanisms have empirical implications that are detectable in the aggregate.

Finally, this article advances work on descriptive representation by including military veterans, which provides two important points of theoretical leverage. First, as Figure 1 indicates, the number of veterans in Congress has declined even while there is broad political consensus favoring veterans' benefits-trends that are typically the reverse in studies of the representation of women and racial/ethnic minorities. The fact that the data still reveal important differences among legislators suggests that the political conflict and partisan cleavages that can characterize other groups' priorities are not necessary for descriptive representation to lead to substantive representation. Our findings, consistent across women, racial/ethnic minorities, and veterans, also suggest that the behavior of descriptive representatives is not solely explained by historical, electoral, and other contextual accounts particular to a single group described in the extant literature. Second, members vary in their degree of shared experience with veterans in ways that are observable. This allows us to empirically assess this critical mechanism of representation often referenced in past work. In keeping with this explanation, we find that substantive representation of veterans is particularly pronounced among legislators who have military service that is not confined to reserves or state national guards.

\section{Descriptive and Substantive Representation in Congress}

Although the extant literature typically focuses on representation through lawmaking, protected classes of citizens may be most vulnerable at the implementation stage of policymaking. Policy implementation is particularly critical for underrepresented communities because it is less visible and often decentralized, involving unelected bureaucrats in numerous agencies and at multiple levels of government. Consequently, even when Congress passes a law, it does not ensure that implementation will be swift or follow legislative intent. For example, research on the Civil Rights Act found that Title VI, 


\section{FIGURE 1 Descriptive Representation in Congress}

(a) House

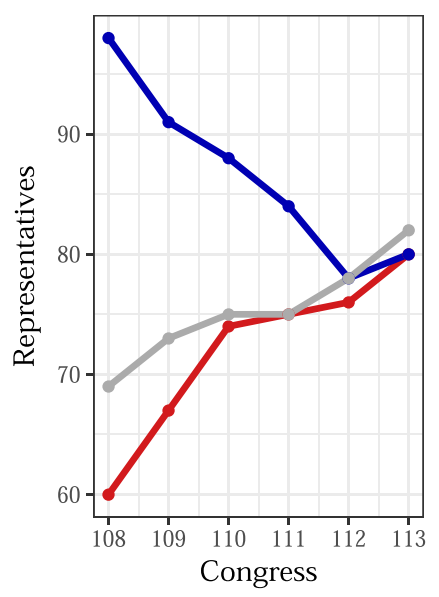

(b) Senate

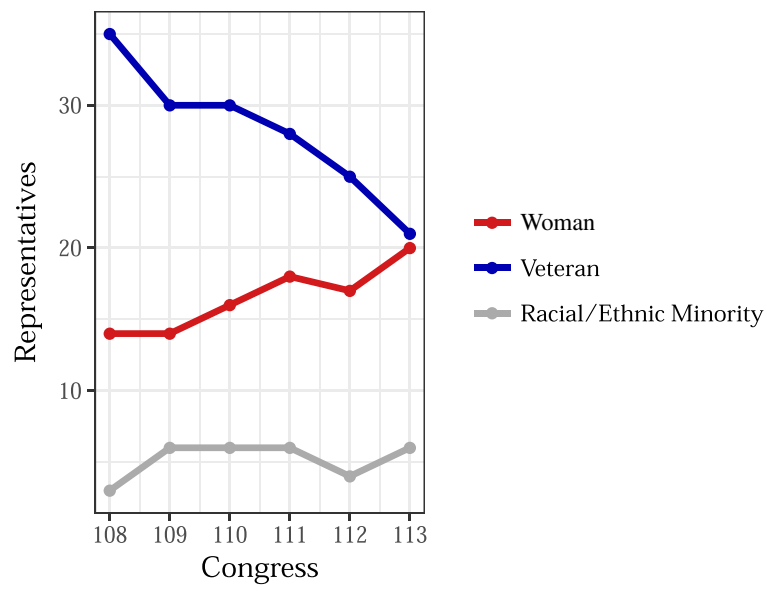

Note: Plots indicate the number of legislators with each identity (CQ Member Profiles); legislators are classified as veterans if their occupational history includes either active-duty or reserve positions.

meant to prohibit organizations that discriminate from receiving federal funding, was stalled by federal agencies (see Minta 2011, 41). Additionally, some sections of the Voting Rights Act, overseen by state-level bureaucrats, were unevenly implemented, depending on the state and its history with civil rights (Marschall and Rutherford 2016). Even when an agency's primary purpose is to serve protected groups, oversight is still necessary. ${ }^{1}$ Take, for instance, complaints during the 1980s that the Equal Employment Opportunity Commission (EEOC) was ineffective in managing cases of workplace civil rights violations (Minta 2011, 54) or the more recent findings that medical records had been falsified at Veterans Affairs (VA), compromising the health care of thousands of citizens. $^{2}$

Protected classes of citizens rely on elected representatives to advocate on their behalf and are dependent on the alacrity of legislators' intervention with unelected bureaucrats. The dependence on legislator intervention is concerning given that modern legislators face an increasingly large set of demands for their attention but a limited set of resources to work with (Curry 2015), and participation in policy implementation and oversight is considered particularly costly with little to gain electorally

${ }^{1}$ While oversight does occur, publicly, in committees, this formal oversight is constrained by party leadership. By contacting agencies directly, legislators can send signals of their priorities, but without waiting for a scheduled hearing and even when they are not on committees with jurisdiction.

${ }^{2}$ Seehttps://www.justice.gov/usao-sdga/pr/va-employee-sentenced -federal-prison-falsifying-medical-records-hundreds-veterans.
(Hall and Miler 2008; McCubbins and Schwartz 1984). Agency oversight occurs largely beyond the purview of the public. In this context, legislators must set priorities, elevating the importance of some issues and tasks at the expense of others-inevitably signaling who they are choosing to represent (Hall 1996). ${ }^{3}$

Some studies suggest legislators who are themselves members of protected groups prioritize the representation of these citizens and, consequently, are more tenacious advocates. For example, a large body of research has focused on whether female and minority legislators behave differently than their male and white counterparts. Often grounded in theories of descriptive representation, many scholars expect that legislators' personal characteristics and experiences will shape their legislative priorities and policy preferences. To the extent that these preferences are shared among the group at large (e.g., women) but are unique among elected officials (who are overwhelmingly male), the presence of descriptive representatives leads to greater substantive representation for that group (Mansbridge 1999). Interviews with legislators and their staff provide preliminary evidence in

${ }^{3}$ Of course, congressional staffers, rather than legislators themselves, are often involved in intervening with agencies. Scholars have long recognized that behavior attributed to legislators (e.g., bill introductions, cosponsorships) is influenced by their staff (Salisbury and Shepsle 1981). However, staffers have an incentive to moderate their behavior to reflect the preferences and priorities of the legislator (Hall 1996), especially when in an official capacity as a representative of their office. Additionally, some work (Grose, Mangum, and Martin 2007) indicates that descriptive representatives hire staff who share their background characteristics. 
favor of this view (Burden 2007; Grose 2011; Swers 2002, 2013).

However, quantitative research on descriptive representation has overwhelmingly focused on roll-call votes with generally mixed results. One explanation for these varied results could be the constraints (e.g., agenda setting) on legislators' voting behavior. Formal legislative activity, like voting, is shaped by crosscutting influences on legislative behavior, including chamber rules or pressure from leadership, forcing members to be more strategic and limiting the extent to which they are free to vote their conscience (or background). Instead, legislators' partisan attachment and district preferences dominate their voting behavior (Hero and Tolbert 1995; Tate 2003). Issues on which we would expect to observe different behavior from minority and women legislators are likely censored from the agenda. Party leaders do not want to schedule votes that will reveal divisions within the party, whether along racial or gender lines. Thus, observing voting behavior alone is likely to depress effects of descriptive representation and exaggerate party unity. Since issues on which we would expect to observe different behavior from minority and women legislators may never make it to the floor for a vote, studies that do find differences are noteworthy. ${ }^{4}$

Existing scholarship examining "proactive" expressions of representation, including bill introductions and committee participation (Burden 2007), provides a clearer consensus that descriptive representation influences responsiveness across gender (e.g., Dodson 2006; Gerrity, Osborn, and Mendez 2007; Swers 2002; Wolbrecht 2000, 2002) and race (e.g., Gamble 2007; Minta 2009, 2011), but effect sizes are often small. ${ }^{5}$ Like roll-call votes, however, these upstream formal legislative behaviors are still public and easily observable, making them susceptible to the same constraints and cross-pressures from constituents, the media, party leadership, and other

${ }^{4}$ Some work concludes that African American (e.g., Canon 1999; Grose 2005; Swain 1993) and Latino (e.g., Fraga, Lopez, MartinezEbers, and Ramirez 2007) legislators vote differently than their white colleagues. In general, women representatives have more liberal voting records, particularly when it comes to "feminist" issues such as abortion (Swers 1998; Welch 1985).

${ }^{5}$ For example, black legislators are more likely than their white colleagues to introduce bills (e.g., Haynie 2001; Tate 2003), participate in committee (e.g., Gamble 2007; Minta 2009, 2011), and make floor speeches (e.g., Canon 1999) on issues of importance to black Americans. Latino legislators introduce more bills related to issues important to Latinos (Bratton 2006). Women prioritize social welfare and issues important to women, reflected in their bill sponsorship, committee participation, and floor behavior (Dodson 2006; Gerrity, Osborn, and Mendez 2007; Swers 2002). Women in Congress bring women's rights to the agenda (Wolbrecht 2000, 2002). members of Congress (e.g., Box-Steffensmeier, Arnold, and Zorn 1997; Crespin 2010; Ritchie 2018). Visibility can hinder the ability for congresswomen to advocate for the interests of women, for example, if they face pressure from co-partisans with more extreme ideological perspectives and wish to maintain choice committee assignments or move into leadership positions (Dodson 2006; Swers 2002). Additionally, external political forces, like an upcoming election, may constrain the behavior of members from protected groups as well. For example, African American members may have an electoral incentive to not appear to be catering to black voters rather than reaching out to their white constituency (Canon 1999; and see Shaw v. Reno, 509 U.S. 630, 1993). Overall, the visibility of legislators' behavior, at any point in the lawmaking process, can depress their ability and motivation to represent protected group interests (cf. Bishin 2009).

A growing body of research considers less visible legislator behaviors. Additional observational studies examining earmarks for protected groups and casework (e.g., Grose 2011; Grose, Mangum, and Martin 2007), find that descriptively representative legislators are more responsive to the groups they represent. Moreover, recent field experiments on state legislators consider responses to constituent emails. Broockman (2013) finds that black state legislators are more likely than white legislators to respond to contacts from black citizens who report living outside their district. Likewise, black state legislators are more likely than their white counterparts to respond to requests for help with registering to vote when sent from black aliases (Butler and Broockman 2011). With regard to gender, although women legislators show a balanced response across women's issues and other issues not related to gender, men tend to show less responsiveness to constituent contact related to women's issues (Butler 2014). These findings suggest that legislators from protected groups work on behalf of protected classes of citizens when their behavior is both public and private-suggesting that their efforts are sincere, as opposed to strategic.

However, this work raises several additional questions. First, it is unclear whether the same mechanisms generalize beyond state legislatures to the U.S. Congress or beyond black and female legislators to other protected groups. Second, and more importantly, it is unclear whether the mechanisms identified have an observable impact on patterns of representation. These questions are critical since experimental results demonstrate striking differences with apparent implications for democratic representation. We build on the existing literature by addressing some unanswered, and unexamined, questions using novel data, and provide clarity to competing 
explanations for the substantive behavior of descriptive representatives.

\section{Interbranch Representation of Protected Groups}

We argue that descriptive representation provides substantive representation through intervention with the bureaucracy for two main reasons. ${ }^{6}$ First, these representatives' backgrounds may give them information and insight into the potential for neglect and mistreatment of the protected communities with which they have shared experiences and a common history (Burden 2007; Mansbridge 1999; Swers 2013). Second, a sense of shared group identification is likely to motivate members of Congress to be diligent advocates for those communities (Burden 2007; Hall 1996; Mansbridge 1999; Minta 2011; Swers 2002). This motivation is important because participation is not universal but is highly selective. Members who have an interest in a certain outcome have to invest more than just votes. When highly motivated, legislators are willing to pay a greater cost (Hall 1996). These shared experiences drive legislators to reign in agency discretion, making them more vigilant watchmen for discriminatory practices and neglect. Thus, these members of protected groups in Congress serve as attentive advocates for citizens of their respective communities.

This interbranch communication between legislators and bureaucrats is important because it can have consequences for policy outcomes. Scholars find, for example, that direct contact from legislators can influence, and even reverse, bureaucratic decision making (Ritchie and You, 2019). This type of communication has the potential to impact how protected classes of citizens experience policies by shaping implementation.

Of course, there are other factors influencing these interventions. Most prominently, citizens of protected communities may be more likely to contact legislators with shared experiences, thus increasing the volume of "fire alarms" for those legislators (Broockman 2014; McCubbins and Schwartz 1984). Existing work, therefore, suggests that both mechanisms may contribute to observed differences. Our study does not challenge this conclusion. However, in supplementary analyses, we find evidence that suggests our findings cannot be attributed wholly to constituent demand-side effects.

${ }^{6}$ We confine our attention to shared identities, rather than advocacy on behalf of underrepresented groups in general. Questions about whether representation in this way is zero-sum across identities is left for future work.

\section{Military Service and Substantive Representation}

By considering military service in addition to race and gender, we investigate open questions about the conditions that lead legislators to advocate for citizens with shared identities and experiences. Although much of the existing literature on descriptive representation focuses on visible characteristics such as race or gender, there is no theoretical reason to limit our focus to physical features (Mansbridge 1999). The experience of being a woman or black shapes the way people see and experience the world in meaningful ways, but so does an individual's profession or having a loved one with health issues (Burden 2007). These other shared experiences can be just as meaningful, if not more important, for certain segments of the population or for certain issue areas (Bishin 2009). Surprisingly, the impact of military experience has been understudied as a form of descriptive representation. At minimum, the fact that veterans are among groups with protected legal status suggests inclusion in studies of descriptive representation is warranted. However, assessing the influence of military service provides two important points of theoretical leverage.

First, past work suggests that political disagreements over government programs with an impact on the wellbeing of women and racial/ethnic minorities are, in part, behind patterns of substantive representation. For example, Swers (2002) argues that legislators are generally risk averse and blame avoidant, and so they tend to avoid issues that could be contentious, including issues that fall within cultural and civil rights debates, such as reproductive rights and affirmative action programs. Thus, descriptive representatives' behavior is important on these controversial issues because it requires intense interest for the legislator to advocate for policies that may carry political risk (Swers 2002, 12). While arriving at a different conclusion than Swers, Grose (2011) also argues that political conflict and rational electoral incentives play a role in the relationship between descriptive and substantive representation. He argues black legislators, tasked with holding together a coalition of white and black voters, use constituency service to serve their black core supporters in a less visible venue that will avoid making white voters feel as though they are not getting their "fair share" (Grose 2011, 28).

In contrast, support for veterans' programs is widely considered nonpartisan. Representation of veterans is not viewed as sacrificing the representation of nonveterans, and veterans' priorities receive broad, bipartisan support and are generally not characterized by the same political conflict as gender and race. Rare exceptions are the 
foreign policy and defense votes used in previous studies, which do not directly implicate the salaries and benefits of those who have served (Bianco 2005; Lupton 2017). ${ }^{7}$ If political conflict is necessary for substantive representation via descriptive representation, then military service backgrounds should not be associated with interventions on behalf of veterans.

Second, existing studies suggest that the shared experiences (e.g., quality of education, proximity to violence) proxied for by background characteristics, rather than the characteristics themselves, are a critical mechanism that leads to substantive representation (Sen and Wasow 2016). In the case of veterans, the degree of shared experience is, in some sense, observable. Members enter office with wide variation in military background; some have 2-3 years of service in state national guards, whereas others have extensive combat experience in foreign wars. If shared experiences are indeed important, we argue this variation should matter: Members with more military service should be more likely to intervene on behalf of veterans. Specifically, veterans, especially those with active duty service in the Army, Navy, Marines, or Air Force, should be more responsive than nonveteran legislators (Hall 1996; Mansbridge 1999). ${ }^{8}$

\section{Measuring Representation with Constituent Inquiries}

A key contribution of this study is to evaluate expectations associated with descriptive and substantive representation using previously unanalyzed records of congressional communication with the bureaucracy. We use these records to construct a measure of legislator intervention on behalf of protected classes of citizens. Beyond the relative novelty of this approach, these data have several virtues. Legislators' communication with agencies is

${ }^{7}$ Whereas Bianco (2005) does not find a difference between veterans and nonveterans in the U.S. House on defense and foreign policy votes, when narrowing the focus to votes that increase congressional oversight over war operations, Lupton (2017) finds that military experience does matter.

${ }^{8}$ The VA offers a wide variety of benefits to U.S. Armed Forces veterans, but who is considered a veteran, and thus becomes eligible for benefits, is narrowly defined (See https://www.every crsreport.com/reports/R42324.html). Most who served in reserves and national guards fail to meet the eligibility requirements for VA benefits. Since even well-intentioned members from an outside group lack full understanding that leads to proactive behavior (Mansbridge 1999), reserve experience, while important, may not lead to the types of behavior we expect to see in this study if we assume shared experience is a mechanism that drives legislator behavior. the ideal place to look for substantive representation because, as Grose $(2011,25)$ argues, legislators "have complete control over decisions related to serving constituents with casework."

Our data also improve upon one past measure of substantive representation: the allocation of "pork" projects. Though these projects provide clear and targeted benefits within a given district, they were still approved by majority coalitions. Since the ban, legislators have been forced to lobby bureaucratic agencies to achieve targeted benefits (Mills, Kalaf-Hughes, and MacDonald 2016). Thus, the outcome is mediated by the executive branch - which many have found allocates funds strategically (e.g., Kriner and Reeves 2015). In contrast, we use records of direct contact (e.g., letters, calls, emails) from members of Congress to bureaucratic agencies on behalf of constituents. We argue this provides a more direct measurement of substantive representation than has been previously available for observational research-limiting the number of alternative explanations for uncovered relationships. Contact data come from correspondence logs maintained by 15 agencies (Lowande 2018, 2019; Mills, Kalaf-Hughes, and MacDonald 2016; Ritchie 2018; Ritchie and You, 2019). ${ }^{9}$ These logs were collected via Freedom of Information Act requests. Overall, our data contain 88,519 usable contacts from legislators as logged by the agencies outlined in Table $1 .^{10}$

Why does legislator intervention with agencies provide meaningful measures of substantive representation? Several of the agencies in question are the principal federal authorities responsible for policies targeted to the groups in question. Title VII of the 1964 Civil Rights Act outlines the EEOC's mission-to enforce prohibitions against discrimination in the workplace. Though these laws prohibit discrimination against any race, color, or national origin and any sex, their intent and effect have been to protect women and racial or ethnic minorities. ${ }^{11}$ The VA's primary mandate is to serve military veterans and their dependents, while operating the largest system

${ }^{9}$ We selected these seven executive departments and eight other agencies based on their jurisdictions, responses to FOIA requests, quality of the records provided, and whether the records provided all of the information and level of detail necessary.

${ }^{10}$ By "usable," we mean cases that identify the contacting legislator, include the contact date, and contain a description of the inquiry. Fewer than 200 cases had to be excluded because one or all of these were missing, or because the contact did not come from a federal elected official.

${ }^{11}$ Note that the EEOC also enforces laws against age and disability discrimination, but the vast majority of cases involve racial/ethnic or sex discrimination. In 2015, the latter made up 78\% of the EEOC's caseload. See https://www.eeoc.gov/eeoc/statistics/ enforcement/index.cfm. 


\section{TABLE 1 Data Coverage for Legislator Interventions}

\begin{tabular}{lccccrr}
\hline Agency & $\mathbf{1 0 9}$ & $\mathbf{1 1 0}$ & $\mathbf{1 1 1}$ & $\mathbf{1 1 2}$ & $\mathbf{1 1 3}$ & $\mathbf{N}$ \\
\hline Armed Forces Retirement Home & & $\sqrt{ }$ & $\sqrt{ }$ & $\sqrt{ }$ & $\sqrt{ }$ & 19 \\
Corp. for National \& Community Service & & & & $\sqrt{ }$ & & 213 \\
Consumer Product Safety Commission & - & $\sqrt{ }$ & $\sqrt{ }$ & - & 339 \\
Department of Education & $\sqrt{ }$ & $\sqrt{ }$ & $\sqrt{ }$ & - & 2,892 \\
Department of Energy & & $\sqrt{ }$ & $\sqrt{ }$ & - & 4,403 \\
Department of Homeland Security & $\sqrt{ }$ & $\sqrt{ }$ & $\sqrt{ }$ & $\sqrt{ }$ & 24,305 \\
Department of Housing and Urban Development & & $\sqrt{ }$ & $\sqrt{ }$ & $\sqrt{ }$ & 8,846 \\
Department of the Interior & & & & $\sqrt{ }$ & 916 \\
Department of Labor & $\sqrt{ }$ & $\sqrt{ }$ & $\sqrt{ }$ & $\sqrt{ }$ & 28,570 \\
Department of Veterans Affairs & & & & $\sqrt{ }$ & 1,109 \\
Equal Employment Opportunity Commission & & $\sqrt{ }$ & $\sqrt{ }$ & $\sqrt{ }$ & $\sqrt{ }$ & 11,951 \\
Environmental Protection Agency & & & $\sqrt{ }$ & $\sqrt{ }$ & $\sqrt{ }$ & 438 \\
Federal Reserve & & & $\sqrt{ }$ & $\sqrt{ }$ & $\sqrt{ }$ & 872 \\
National Science Foundation & & $\sqrt{ }$ & $\sqrt{ }$ & $\sqrt{ }$ & 895 \\
U.S. Agency for International Development & & &
\end{tabular}

Note: Checkmark indicates records include full date coverage of Congress; dash indicates partial coverage.

of health care facilities in the United States. They are the federal government's arbiter of disability compensation, retirement benefits, financial services, and medical care of veterans.

Other agencies in our data also have jurisdiction over statutes that offer opportunities for substantive representation. The Department of Education is charged with enforcing Title IX regulations at colleges and universities. The Department of Labor enforces the Uniformed Service Employment and Reemployment Rights Act (USERRA), which assists service members with problems maintaining employment. Even agencies without specifically targeted laws often run programs with group-specific relevance. The Department of Energy maintains an office dedicated to promoting research at minority-serving educational institutions. Moreover, since the early 1960s, presidents have used their authority to promote government-wide diversity in grant writing and contracting (Gitterman 2017). All agencies that engage in either activity must adhere to these standards. This creates yet another opportunity for legislator interventions. Put simply, legislative interventions that serve the interests of women, racial/ethnic minorities, and veterans are likely to go through these agencies' offices.

Nonetheless, these data do have limitations that are important to present. Our sample of agencies is limited to those responding to FOIA requests and to the time series they provide. Often, agencies are reticent to release records for a long time series because of a labor-intensive review and redaction process. This is especially true in large agencies. As a result, coverage of particular congresses varies by agency. As Table 1 indicates, our records of intervention are most highly concentrated in the 110th, 111th, and 112th Congresses.

This raises a few potential concerns. First, the volume of contact will vary by congress because of arbitrary differences in our data coverage. Second, the presence or absence of particular agencies with high volumes of representation contact could bias a given congress toward higher counts. For example, diversity in Congress is trending upward, so the introduction of the EEOC correspondence $\log$ in the 110th Congress could create a spurious association between our key independent and dependent variables. We take two steps to address these concerns. First, we dichotomize the key dependent variables, which are coded 1 for at least one intervention on behalf of a particular group in a given congress, and 0 otherwise. This reduces the potential for error by collapsing variation in the count of contact that may be due to the coverage issues discussed above. Second, we provide multiple specifications of each dependent variable that exclude agencies for which we do not have complete coverage from the 110th112th Congresses. Reassuringly, we find that our results are generally not sensitive to arbitrary inclusion or exclusion of particular congresses. When this is not the case, we explicitly note it in our presentation of the results.

Our aim is to identify cases of substantive representation of legally protected classes. Specifically, our dependent variables are intended to measure legislators' intervention with federal agencies on behalf of either racial or 
ethnic minorities, women, or veterans. Each intervention on behalf of a protected class is considered separately. All correspondence descriptions were read and hand-coded by the authors. The coding definitions, procedures, examples, and inter-coder reliability diagnostics can be found in Appendix A of the supporting information (SI; A1). In short, we coded a contact as a relevant intervention if the description provided by the agency indicated that the legislator was working on behalf of, supporting, or advocating for an individual or a group of individuals who are legally protected. Only cases of positive representation of protected classes were included in the dependent variables. In other words, contacts describing a constituent opposing protections for protected classes were not coded affirmatively. ${ }^{12}$

To be coded affirmatively, the description had to explicitly support the group in question. By "explicit," we do not mean that the contact necessarily had to contain the word, woman or African American, but that the support for veterans, women, or racial and ethnic minorities had to be clear and narrowly defined. For example, if a contact description read, "in support of the NAACP" or "in support of Morehouse College," it would be coded as a case of substantive representation of a racial/ethnic minority. This means that we did not include contacts that were about issues that have been broadly defined, for example, as "women's issues" (e.g., child health or education) in previous literature. Moreover, the group supported cannot be ambiguous. For example, occasionally, the EEOC notes that a constituent "alleges discrimination" without referencing the type of discrimination (e.g., sex, age, race/ethnicity, disability). These cases were excluded. For this reason, if anything, our data may slightly undercount relevant interventions.

The policy content of substantive representation varies dramatically by agency and can address the concerns of a particular constituent or the group as a whole. For example, employment-related contacts may advocate on behalf of a constituent with a discrimination case or ask the agency to provide detailed information about its plans for hiring a diverse workforce. Likewise, grant-related contacts may be letters of support for specific applicants or inquiries about grants available for

\footnotetext{
${ }^{12}$ One potential concern is that legislators may strategically reference legally protected groups in order to improve the odds of influencing agency behavior-even when the policy in question does not directly implicate that group alone. For example, a legislator may add "as a veteran" to his or her letter to increase the odds of influencing environmental regulation. Importantly, the correspondence logs provide no opportunity for this kind of behavior, as they are terse summaries of the policy or program implicated and are free of any references to legislators' identities, motivations, or arguments.
}

the benefit of veterans, women, or racial/ethnic minorities. Additional examples are reported in Appendix A of the SI (A2).

\section{Research Design}

Our empirical strategy is to compare the group-specific interventions of legislators who do and do not descriptively represent particular constituent groups. For all models, our unit of analysis is legislator-congress, and the dependent variable is a dichotomous indicator for intervention on behalf of the group in question. Since we test our expectations in the context of each group separately, the precise variables and functional form of each analysis will differ. However, in general, our approach is to estimate the effect of each legislator's descriptive characteristic while accounting for potential confounders. Most importantly, our aim is to account for selection into being represented by a legislator with various backgrounds. For each group, we evaluate this in three ways: simple difference-of-means among split-Senate delegations, cross-sectional regression controlling for confounders, and coarsened-exact matching. Our results are largely consistent across each. We confine the main text to the discussion and presentation of substantively interpretable marginal effects, with full results reported in the SI.

Prior to presenting these results, it is important to reiterate two points about identification. First, since candidate selection is explicitly endogenous to constituent preferences, our analysis is properly thought of as descriptive. Second, and relatedly, our analysis is not intended to adjudicate between alternative causal mechanisms examined by previous experimental research. As Butler (2014) notes, politicians may have strategic and nonstrategic reasons to prioritize certain requests and perform casework. That is, they may prioritize serving electorally relevant constituents or exhibit personal bias (Butler and Broockman 2011). Moreover, descriptive characteristics may influence the likelihood constituents choose to contact legislators at all (Broockman 2014). Importantly, each of these potential mechanisms suggests the same relationship: that descriptive representation ought to translate into substantive representation. Thus, support for our hypotheses should be taken as evidence that one or more of these causal mechanisms has meaningful implications that are observable in the aggregate. We revisit questions about these mechanisms when discussing our results.

Legislator background was coded using CQ Press's congressional member profiles. Sex and race/ethnicity are taken directly from these records. The lack of diversity 
in Congress limits our ability to make inferences about any particular race or ethnicity. For the purposes of this analysis, the key independent variable is a dichotomous indicator for racial/ethnic minority background. With few exceptions, legislators were coded as having military service if they satisfied the federal definition of veteran, which includes two criteria: active-duty service followed by discharge via some means other than dishonorable. ${ }^{13}$ To assess the relative influence of shared experience, we also provide an alternative measure that excludes legislators who would be classified as reservists in common parlance: those who served exclusively in reserve components of the armed forces (e.g., Army/Navy Reserve, Air National Guard) or in state national guards.

For each group, we leverage multiple potential measures to account for member selection. Figure 2 plots each measure alongside its corresponding legislator characteristic. For constituents with military service, we use veteran population (VetPop) or total VA expenditures by district. These data are aggregated and maintained by the VA (Figure 2b). Importantly, however, the VetPop survey data are imputed by unknown means, and the VA does not report corresponding error estimates. Thus, we regard reported expenditures as more reliable. They are correlated with selection of a legislator with military service (Figure 2a). For gender and race/ethnic background, we use estimates of district ideology developed by Tausanovitch and Warshaw (2013). We plot these in Figure 2d. District liberalism is correlated with selection in both cases. Finally, for race/ethnic background, we also use district race/ethnicity population estimates (Figure 2f). Each of these measures is modestly correlated in the expected direction with our key independent variables. All regression models will also include chamber and Congress fixed effects to account for time-specific shocks, so our results leverage variation between samechamber legislators within a given congress. Since our models are meant to account for factors that lead to the selection of representative legislators, we refrain from presenting results with an exhaustive set of potential covariates. Nonetheless, SI Appendix B reports additional results with controls for poverty, legislator seniority, and state fixed effects. In general, the results we present in text are robust to these specifications.

We are also cognizant of the basic limitations of our time-series and data availability. One general concern is that the number of veterans, women, and racial/ethnic

\footnotetext{
${ }^{13}$ Mitch McConnell, for example, satisfies both criteria, but served for 3 months in the Army Reserve and secured a medical discharge for an ailment (optic neuritis), which was cured months after. Veteran interest groups unanimously omit McConnell from public lists of "legislators who served."
}

minorities in Congress will limit our ability to confidently detect differences across groups. To investigate this, we conducted a simulation study of congressional representation during this period (Appendix C, A9-A10). We find that the research design described above recovers the effect for veterans in $75 \%$ of simulations if the true effect for veterans is greater than a 0.55 standard deviation. Predictably, our design is less effective at recovering the effects for gender and race/ethnicity. For race/ethnicity, the effect size would have to be implausibly large ( 1.5 standard deviations) to hit the same $75 \%$ threshold. This illustrates a basic point: that our analysis likely biases against finding affirmative evidence of descriptive representation for women and racial/ethnic minorities, providing a conservative test of the link between descriptive and substantive representation.

\section{Findings}

Overall, we find consistent evidence that descriptive representation matters for substantive representation in Congress. There are substantively significant differences in the content of interventions by legislators' military service, gender, and race/ethnicity. These differences persist after accounting for confounders and "pruning" the data set to comparable units. The most striking differences are among male and female legislators, with women in Congress around 8 percentage points more likely to contact agencies on behalf of women. This is particularly striking because the baseline probability of such contact is around 20 percentage points. We also find that the degree of shared experience matters for substantive representation. The differences in veteran interventions are driven by legislators with active-duty service in the Army, Navy, Marines, or Air Force. That is, legislators who served in their states' national guard or in reserves do not meaningfully differ in their volume of interventions from those with no military background. These findings suggest that shared experience operates as a critical mechanism for representation.

\section{Military Service}

Table 2 reports differences in mean veteran interventions across legislator groups. For each analysis that follows, the dependent variable is a dichotomous indicator for at least one group-specific intervention in a given congress, so the results can be interpreted as conditional probabilities. We present differences for all legislators, 


\section{FIGURE 2 Representatives and the Represented}

(a) Members with Military Service

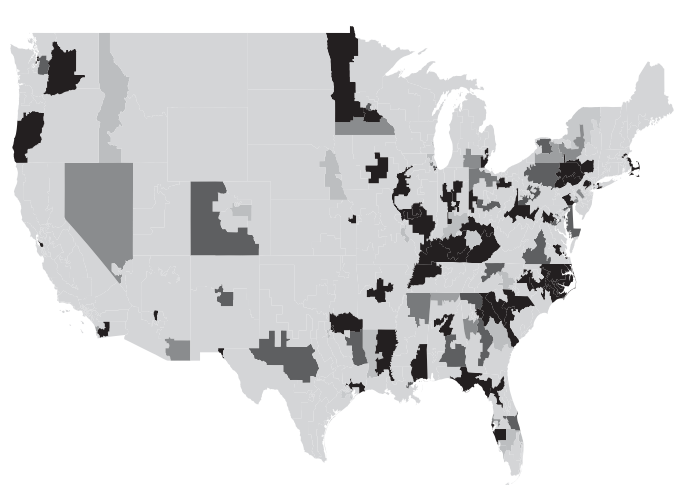

(b) Veteran Constituents

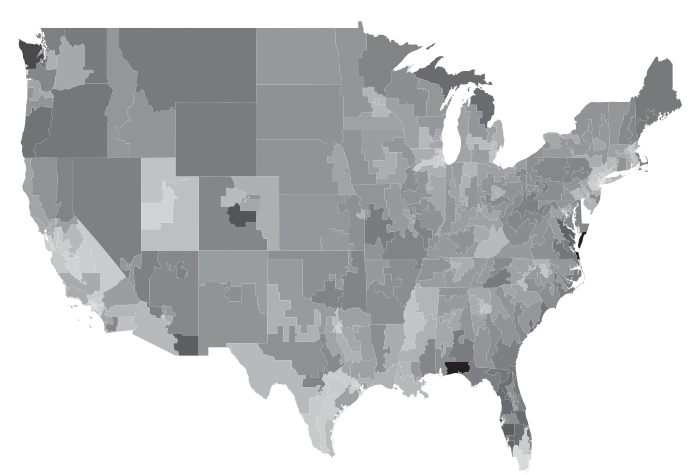

Note: Plots indicate proportion of legislators with military service from the 108-111th Congresses, and of the population who are veterans; darker shades indicate higher values.

(c) Women in the House

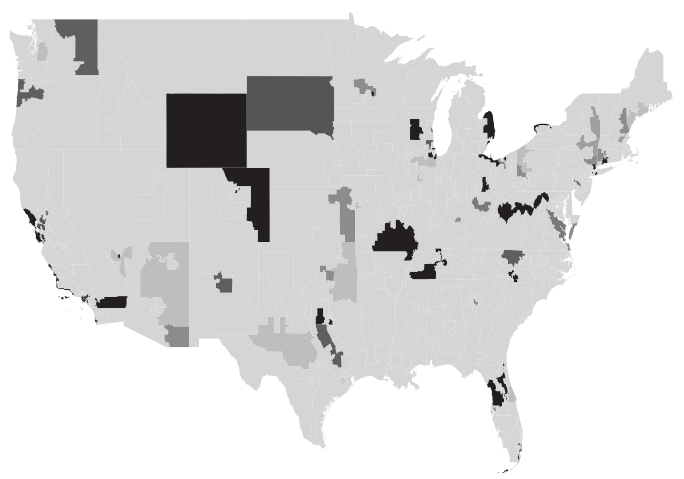

(d) District Ideology

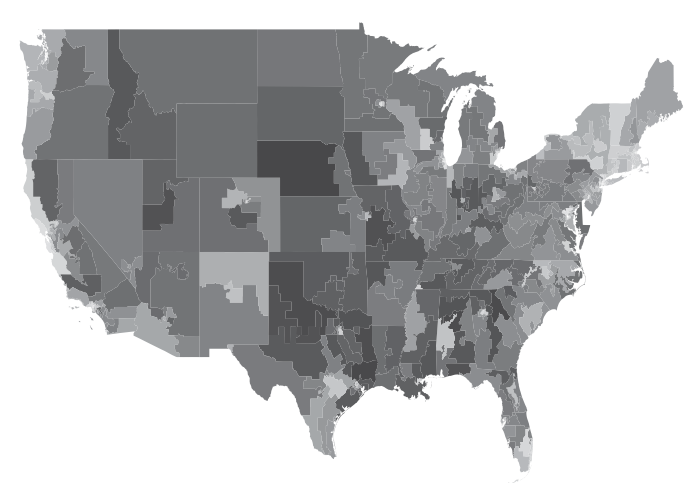

Note: Plots indicate proportion of female legislators serving from the 108-111th Congresses, and the ideology of each district, according to Tausanovitch and Warshaw (2013); darker shades indicate higher values.

(e) Race/Ethnicity in the House

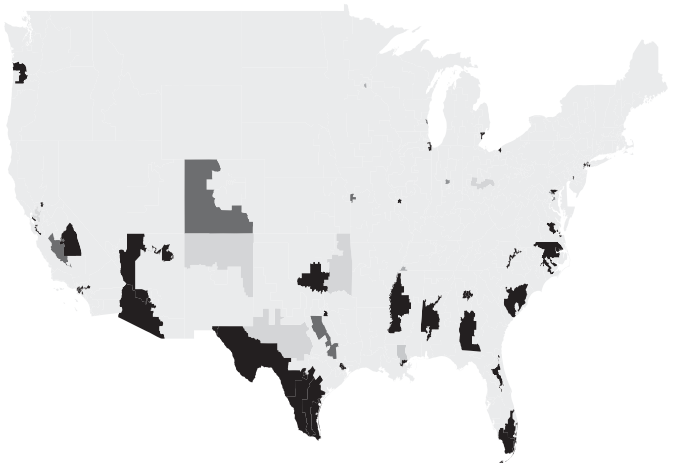

(f) Race/Ethnicity of Constituents

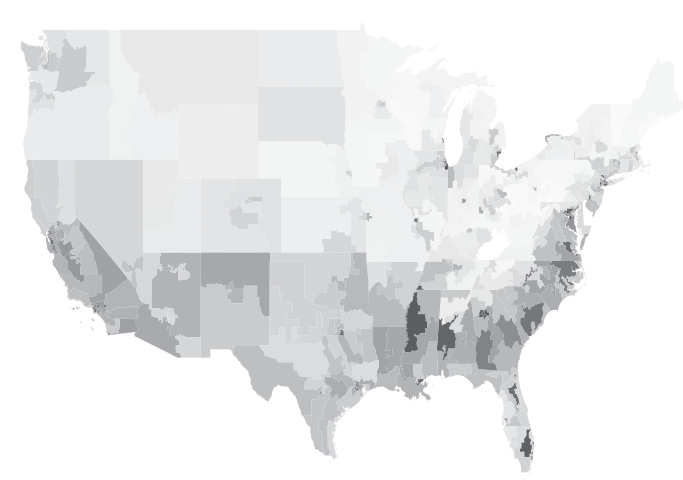

Note: Plots indicate proportion of legislators with racial/ethnic minority background serving from the 108-111th Congresses, and the nonwhite population of each district; darker shades indicate higher values. 
TABLE 2 Representation Differences across Members with Military Service

\begin{tabular}{lccc}
\hline Any Veteran & Nonveterans & Veterans & Difference (95\% CI) \\
\hline $\begin{array}{l}\text { All Legislators } \\
(\mathrm{n}=2194)\end{array}$ & 0.25 & 0.31 & $+0.06[0.01,0.10]$ \\
$\begin{array}{l}\text { Split-Senate Delegations } \\
(\mathrm{n}=170)\end{array}$ & 0.44 & 0.60 & $+0.16[0.01,0.31]$ \\
$\begin{array}{l}\text { Excluding Reservists } \\
\text { All Legislators }\end{array}$ & Nonveterans & Veterans & Difference (95\% CI) \\
$(\mathrm{n}=2194)$ & 0.25 & 0.34 & $+0.09[0.04,0.15]$ \\
$\begin{array}{l}\text { Split-Senate Delegations } \\
(\mathrm{n}=110)\end{array}$ & 0.43 & 0.65 & $+0.22[0.04,0.41]$ \\
\hline
\end{tabular}

Note: Dependent variable is a dichotomous indicator of intervention on behalf of veterans in the agencies in Table 1; the unit of analysis is legislator-congress; means and difference of means are by subgroup; split-Senate delegations are those with one member with military service.

\section{TABLE 3 Military Service and Veterans Representation}

\begin{tabular}{|c|c|c|c|c|}
\hline & \multicolumn{4}{|c|}{ Dependent Variable } \\
\hline & \multicolumn{2}{|c|}{ All Contact } & \multicolumn{2}{|c|}{ 110th-112th Cong. } \\
\hline & $(1)$ & $(2)$ & $(3)$ & $(4)$ \\
\hline Veteran (Any) & $\begin{array}{c}0.029 \\
(0.024)\end{array}$ & & $\begin{array}{c}0.047 \\
(0.028)\end{array}$ & \\
\hline Veteran (Excluding Reservists) & & $\begin{array}{c}0.068 \\
(0.030)\end{array}$ & & $\begin{array}{c}0.072 \\
(0.032)\end{array}$ \\
\hline Commonspace Ideology & $\begin{array}{r}-0.016 \\
(0.022)\end{array}$ & $\begin{array}{r}-0.016 \\
(0.022)\end{array}$ & $\begin{array}{r}-0.030 \\
(0.025)\end{array}$ & $\begin{array}{r}-0.030 \\
(0.25)\end{array}$ \\
\hline $\ln$ (Veteran Expenditures) & $\begin{array}{c}0.073 \\
(0.015)\end{array}$ & $\begin{array}{c}0.073 \\
(0.015)\end{array}$ & $\begin{array}{c}0.070 \\
(0.019)\end{array}$ & $\begin{array}{c}0.071 \\
(0.019)\end{array}$ \\
\hline $\begin{array}{l}\text { Congress Fixed Effects } \\
\mathrm{N}\end{array}$ & $\begin{array}{c}\sqrt{ } \\
2,194\end{array}$ & $\begin{array}{c}\sqrt{ } \\
2,194\end{array}$ & $\begin{array}{c}\sqrt{ } \\
1,654\end{array}$ & $\begin{array}{c}\sqrt{ } \\
1,654\end{array}$ \\
\hline Adjusted $\mathrm{R}^{2}$ & 0.15 & 0.16 & 0.09 & 0.09 \\
\hline
\end{tabular}

Note: "All Contact" is a dichotomous indicator for intervention on behalf of veterans in the agencies in Table 1; " 110 th-112th" is a subset of these congresses for the agencies with whom we have a complete record; the unit of analysis is legislator-congress; least squares coefficients with standard errors are clustered by legislator in parentheses; all models control for chamber; Congress intercepts are omitted for readability.

as well as split-Senate delegations. These are pairs of senators in a given congress who represent the same state but have different backgrounds. This allows us to hold constituency constant. In each case, there are consistent and substantively significant differences across legislators with military experience. These differences are stronger when those who served solely in reserves or national guards are not coded as veteran legislators. It is also larger for split-Senate delegations. In general, senators intervene with agencies more frequently, so the baseline probability of contact is higher. Senators with military service are 22 percentage points more likely to perform veteran-related interventions than their nonveteran, same-state colleagues.

These differences are robust to accounting for various confounders and alternative measures of representation. In Table 3, we report least squared estimates that control for legislator ideology and logged veteran expenditures. As Models 2 and 4 indicate, differences in interventions are primarily driven by veterans with more than reserve or national guard experience. In Model 4, veterans are about 7 percentage points more likely to contact an agency on behalf of veterans. Inclusion of confounders that should contribute to legislator selection may bias these estimates. 


\section{TABLE 4 Representation Differences across} Gender

\begin{tabular}{lccc}
\hline & Male & Female & $\begin{array}{c}\text { Difference } \\
(\mathbf{9 5 \%} \text { CI })\end{array}$ \\
\hline $\begin{array}{l}\text { All Legislators } \\
(\mathrm{n}=2194)\end{array}$ & 0.11 & 0.23 & $+0.12[0.07,0.16]$ \\
$\begin{array}{l}\text { Split-Senate } \\
\text { Delegations }\end{array}$ & 0.13 & 0.34 & $+0.21[0.02,0.40]$ \\
$(\mathrm{n}=76)$ & & & \\
\hline
\end{tabular}

Note: Dependent variable is a dichotomous indicator for intervention on behalf of women in the agencies in Table 1; the unit of analysis is legislator-congress; means and difference of means are by subgroup; split-Senate delegations are those with one female member.

To account for the concern, we report results from a data set matched on each covariate in the SI. As SI Table B2 indicates, this largely replicates the findings reported in Tables 2 and 3 (A3). Restricting our analysis to the agencies for which we have complete coverage from the 110th112th Congresses does not alter these results.

We do, however, find several inconsistencies in these results. One comes when we restrict analysis to the 112th Congress (SI Table B1, A3). This is the congress for which we have the most data, as it includes the log from the Department of Veterans Affairs. Though the estimates are the expected sign, the confidence intervals are wider because of the reduction in sample size. A second is that these results are not robust to the inclusion of additional controls-specifically, seniority and state fixed effects. We report these results in SI Table B3. The effects are "marginally" significant at conventional levels $(\mathrm{p}<.1)$ and in the expected direction (A4). But again, this underscores the inherent difficultly of uncovering systematic differences across groups with our limited time series.

\section{Gender}

We find striking differences in legislator intervention across gender. Table 4 reports significant difference-inmeans estimates for all legislators and split delegations. The marginal increase in each case is large enough to merit skepticism. However, it is noteworthy that rates of contact are statistically distinguishable even after reducing the sample size to the 76 senators in split delegations. This provides a preliminary indication of important differences in women's representation to administrative agencies.

The multivariate results in Table 5 support these differences. Women in Congress are about 8 percentage

\section{TABLE 5 Gender and Women's Representation}

\begin{tabular}{lcc}
\hline & $(1)$ & $(2)$ \\
\hline Female & 0.079 & 0.083 \\
& $(0.020)$ & $(0.021)$ \\
Commonspace Ideology & -0.196 & \\
& $(0.015)$ & \\
District Ideology & & -0.256 \\
& & $(0.024)$ \\
Congress Fixed Effects & $\sqrt{ }$ & $\sqrt{ }$ \\
N & 2,194 & 2,194 \\
Adjusted R & & 0.19 \\
\hline
\end{tabular}

Note: Dependent variable is a dichotomous indicator for intervention on behalf of women in the agencies in Table 1; the unit of analysis is legislator-congress; least squares coefficients with standard errors are clustered by legislator in parentheses; all models control for chamber; Congress intercepts are omitted for readability.

points more likely to intervene on behalf of women. Reassuringly, other covariates exhibit expected relationships with agency contact. Legislators with more conservative voting records or who have more conservative districts are less likely to perform this kind of service. We take this as evidence that our dependent variable is measuring theoretically relevant substantive representation. ${ }^{14}$ Again, these estimates are robust to excluding observations without comparable cases, or including additional controls and state fixed effects. SI Table B5 reports regression estimates for a data set matched with chamber, congress, and measures of district preferences (A5). SI Table B6 reports estimates that include additional controls (A6). Substantive findings across these analyses are consistent.

\section{Race, Ethnicity, and National Origin}

We report least squared estimates for the substantive representation of racial/ethnic minorities in Table 6 . For this section, we forgo presenting difference-of-means results because-as Figure 1 indicates - the number of comparison cases is small. This means that differences across the full sample are noisy, and limiting comparisons to splitSenate delegations is essentially meaningless. Nonetheless, there are some noteworthy differences in Table 6. Though the results are somewhat inconsistent across

\footnotetext{
${ }^{14}$ Our analyses suggest that legislators who are members of protected classes advocate more for issues of importance to those classes. However, our coding procedure provides a narrow definition of women's issues (e.g., violence against women, reproductive rights) and does not include topics, such as children's issues or education, that have been included in broader definitions of women's issues in some previous studies.
} 


\section{TABLE 6 Race/Ethnicity and Minority Representation}

\begin{tabular}{lcccc}
\hline & \multicolumn{4}{c}{ Dependent Variable } \\
\cline { 2 - 3 } & \multicolumn{2}{c}{ All Contact } & & 110th-112th Cong. \\
\cline { 2 - 3 } \cline { 5 - 5 } & $(\mathbf{1})$ & $(\mathbf{2})$ & $(3)$ & $(\mathbf{4})$ \\
\hline Nonwhite & 0.091 & 0.060 & 0.090 & 0.078 \\
& $(0.034)$ & $(0.039)$ & $(0.037)$ & $(0.043)$ \\
District & -0.153 & & -0.203 & \\
$\quad$ Ideology & $(0.041)$ & & $(0.043)$ & \\
District \% & & -0.276 & & -0.264 \\
$\quad$ White & & $(0.075)$ & & $(0.082)$ \\
Congress & $\sqrt{ }$ & $\sqrt{ }$ & $\sqrt{ }$ & $\sqrt{ }$ \\
$\quad$ Fixed & & & & \\
$\quad$ Effects & & & & \\
N & 2,194 & 2,194 & 1,654 & 1,654 \\
Adjusted $\mathrm{R}^{2}$ & 0.11 & 0.12 & 0.11 & 0.11 \\
\hline
\end{tabular}

Note: "All Contact" is a dichotomous indicator for intervention on behalf of a racial/ethnic minority in the agencies in Table 1; "110th112 th" is subset of these congresses for the agencies with whom we have a complete record; unit of analysis is legislator-congress; least squares coefficients with standard errors are clustered by legislator in parentheses; all models control for chamber; Congress intercepts are omitted for readability.

measures of constituency demand, there appears to be a positive relationship between descriptive and substantive representation. In models that account for district ideology, the difference is about 9 percentage points. Again, the baseline probability of such contact is low (about 30\%), so this difference is large and substantively meaningful.

These estimates are less certain when controlling for nonwhite district population in the multivariate models. Importantly, however, the matching results reported in SI Table B8 show more consistent differences (A7). After dropping several hundred white legislators with no plausibly comparable legislator from a different racial/ethnic background, there is about a 10 percentage point difference in the probability of constituency contact. The results are similar after including district poverty rate and legislator seniority as covariates, or state fixed effects to account for unobserved heterogeneity across delegations (SI Table B9, A8).

\section{Mechanisms}

Notably, the analyses above did not distinguish between two alternative (though not mutually exclusive) causal pathways: Legislators are more likely to represent groups with whom they share identities because shared back- grounds motivate members to be more diligent advocates or because constituents from those groups are more likely to contact them. However, since recent work on representation has emphasized delineating between these potential mechanisms (Broockman 2013, 2014; Butler 2014; Butler and Broockman 2011), we investigate differences in types of legislator interventions. From our sample of legislator interventions, we removed categories principally concerned with "casework" from individual constituents: complaints about employment discrimination, denials of government benefits, and grant support letters. This leaves comments on existing laws, pending regulations, or "other" requests that often take the form of general requests for action or for transparency about government programs. By limiting the sample to these more general requests, we have excluded most cases driven by direct contact from constituents. If the previous results were entirely a function of variation in constituent willingness to contact their legislators, we would not expect substantively meaningful differences across legislators for this alternative dependent variable.

We report the results in Tables B4, B7, and B10 of the SI (A4-A8). Importantly, our results do not differ substantively after excluding those cases. Members with military service backgrounds, female members, and members of racial/ethnic minority heritage are still distinguishable from their colleagues in the likelihood they intervene on behalf of the groups with whom they share identities. We cannot guarantee that interventions with more general policy-related aims do not have some unobserved constituent contact motivating them. But after excluding cases in which such motivations are obvious, our data still show meaningful differences across legislators. This suggests that our results are not driven solely by the willingness of constituents to bring their concerns to legislators.

\section{Discussion}

Does descriptive representation improve advocacy for protected communities in policy implementation? We find that legislators are active advocates on behalf of protected classes with whom they have shared backgrounds. These results are consistent across women, racial and ethnic minorities, and military veterans in Congress. These findings offer several contributions.

First, they establish the importance of descriptive representation for interbranch representation of protected groups using a novel and important legislative behavior. Representation is difficult to evaluate by focusing on voting, bill sponsorship, committee participation, and 
pork - which are shaped by a range of constraints including leadership agenda setting, logrolling, and partisan pressures. In short, our results provide a cleaner test of the implications of descriptive representation.

Second, the inclusion of veterans in a study of descriptive representation provides theoretical leverage on why legislators represent those with whom they share identity characteristics. Military service is a unique comparison case that highlights the importance of shared experience. Previous studies often argue that minorities and women are more active advocates on behalf of their communities, but this is not conventional wisdom about the shared experience of military service. Unlike race and gender, veteran status is not a physical feature. Yet, we find this shared experience is important. Moreover, the nuance within our findings offers insight into the theoretical underpinnings of how descriptive representation in Congress reflects onto patterns of interbranch interactions. For instance, military service alone does not inspire legislators to be active advocates for veterans. The differences in veteran advocacy are driven by legislators with active- duty service, whereas reserve and national guard service does not offer meaningful differences. This result suggests that shared experience improves legislators' representation through interbranch interactions.

Third, our results-which are consistent across women, racial/ethnic minorities, and veterans_-suggest that political conflict may not be necessary for the relationship between descriptive and substantive representation in Congress to hold. Scholars generally think of Congress and the public-regardless of party, ideology, or background-as supportive of veterans. This runs counter to previous arguments that political conflict provides the context for patterns of descriptive representation.

Finally, our findings provide important context for experimental research by using observational data to examine representation within the context of the U.S. Congress and by considering the quality of legislators' advocacy on behalf of citizens. Shared identity not only affects legislators' correspondence-based responses to mail from citizens of protected groups, but also reflects their interbranch advocacy as well. This distinction is important because legislators' informal interventions can affect outcomes for constituents (Ritchie and You, 2019). This is the first study to analyze informal legislator interventions on behalf of protected classes.

Of course, this study has limitations. For example, the underrepresentation of women, minorities, and veterans in Congress poses a challenge for reliable statistical inference. In an effort to assess this limitation, we have conducted a power analysis included in Appendix C of the SI (A9). Additionally, it is important to reiterate our analysis is descriptive. Our research design is unable to adjudicate between causal mechanisms and should be considered in the broader context of recent experimental work on legislative representation.

These limitations notwithstanding, our findings offer several potential implications for representation in Congress. Distinguishing between these competing explanations is important for understanding the impact of descriptive representation as the number of women, minorities, and veterans in Congress changes. Our results offer a somewhat optimistic outlook for the representation of women, minorities, and veterans as Congress becomes more diverse. If, as some argue, the substantive outcomes of descriptive representation are electorally motivated or particular to the electoral context of a single group, it suggests that the substantive outcomes attributed to descriptive representatives may not remain constant over time. However, if, as we argue, the shared experience of these legislators allows them to more adequately assist constituents with the least understood venue of representation, it suggests that the connection between descriptive and substantive representation is likely more stable.

More broadly, our study suggests that underrepresentation in Congress may also have undesirable implications for policy implementation. Since public policy is largely made through agency decisions rather than statutory enactment, it is important for subsequent studies assessing the quality of representation of protected communities to examine the backchannels of bureaucratic governance. Most administrative decisions and interactions with citizens occur outside of the public view, and the incentives of legislators may not offer citizens equal representation in this arena.

\section{References}

Bianco, William T. 2005. "Last Post for 'The Greatest Generation': The Policy Implications of the Decline of Military Experience in the U.S. Congress." Legislative Studies Quarterly 30(1): 85-102.

Bishin, Benjamin. 2009. Tyranny of the Minority: The Subconstituency Politics Theory of Representation. Philadelphia, PA: Temple University Press.

Box-Steffensmeier, Janet M., Laura W. Arnold, and Christopher J. W. Zorn. 1997. "The Strategic Timing of Position Taking in Congress: A Study of the North American Free Trade Agreement." American Political Science Review 91(2): 324-38.

Bratton, Kathleen A. 2006. "The Behavior and Success of Latino Legislators: Evidence from the States.” Social Science Quarterly 87(5): 1136-57.

Broockman, David E. 2013. "Black Politicians Are More Intrinsically Motivated to Advance Blacks' Interests: A Field 
Experiment Manipulating Political Incentives.” American Journal of Political Science 57(3): 521-36.

Broockman, David E. 2014. "Distorted Communication, Unequal Representation: Constituents Communicate Less to Representatives Not of Their Race." American Journal of Political Science 58(2): 307-21.

Burden, Barry C. 2007. Personal Roots of Representation. Princeton, NJ: Princeton University Press.

Butler, Daniel M. 2014. Representing the Advantaged: How Politicians Reinforce Inequality. New York: Cambridge University Press.

Butler, Daniel M., and David E. Broockman. 2011. "Do Politicians Racially Discriminate Against Constituents? A Field Experiment on State Legislators." American Journal of Political Science 55(3): 463-77.

Canon, David T. 1999. Race, Redistricting, and Representation: The Unintended Consequences of Black Majority Districts. Chicago: University of Chicago Press.

Crespin, Michael H. 2010. "Serving Two Masters: Redistricting and Voting in the U.S. House of Representatives." Political Research Quarterly 63(4): 850-59.

Curry, James M. 2015. Legislating in the Dark: Information and Power in the House of Representatives. Chicago: University of Chicago Press.

Dodson, Debra L. 2006. The Impact of Women in Congress. Oxford: Oxford University Press.

Fraga, Luis Ricardo, Linda Lopez, Valerie Martinez-Ebers, and Ricardo Ramirez. 2007. "Gender and Ethnicity: Patterns of Electoral Success and Legislative Advocacy among Latina and Latino State Officials in Four States." Journal of Women, Politics, and Policy 28(3-4): 121-45.

Gamble, Katrina L. 2007. "Black Political Representation: An Examination of Legislative Activity." Legislative Studies Quarterly 32(3): 421-47.

Gerrity, Jessica C., Tracy Osborn, and Jeanette Morehouse Mendez. 2007. "Women and Representation: A Different View of the District?” Politics \& Gender 3(2): 179-200.

Gitterman, Daniel P. 2017. Calling the Shots: The President, Executive Orders, and Public Policy. Washington, DC: Brookings Institution Press.

Grose, Christian R. 2005. "Disentangling Constituency and Legislator Effects in Legislative Representation: Black Legislators or Black Districts?" Social Science Quarterly 86(2): 427-43.

Grose, Christian R. 2011. Congress in Black and White: Race and Representation in Washington and at Home. New York: Cambridge University Press.

Grose, Christian R., Maurice Mangum, and Christopher Martin. 2007. "Race, Political Empowerment, and Constituency Service: Descriptive Representation and the Hiring of African-American Congressional Staff." Polity 39(4): 449-78.

Hall, Richard L. 1996. Participation in Congress. New Haven, CT: Yale University Press.

Hall, Richard L., and Kristina C. Miler. 2008. "What Happens After the Alarm? Interest Group Subsidies to Legislative Overseers." Journal of Politics 70(4): 990-1005.

Haynie, Kerry L. 2001. African American Legislators in the American States. New York: Columbia University Press.
Hero, Rodney E., and Caroline J. Tolbert. 1995. "Latinos and Substantive Representation in the U.S. House of Representatives: Direct, Indirect, or Nonexistent?" American Journal of Political Science 39(3): 640-52.

Kriner, Douglas L., and Andrew Reeves. 2015. The Particularistic President: Executive Politics and Political Inequality. New York: Cambridge University Press.

Krippendorf, Klaus. 2004. Content Analysis: An Introduction to Its Methodology. Thousand Oaks, CA: Sage.

Lowande, Kenneth. 2018. "Who Polices the Administrative State?" American Political Science Review 112(4): 874-90.

Lowande, Kenneth. 2019. "Politicization and Responsiveness in Executive Agencies." The Journal of Politics 81(1): 33-48.

Lupton, Danielle L. 2017. "Out of the Service, into the House: Military Experience and Congressional War Oversight." Political Research Quarterly 70(2): 327-39.

Mansbridge, Jane. 1999. "Should Blacks Represent Blacks and Women Represent Women? A Contingent 'Yes'.” Journal of Politics 61(3): 628-57.

Marschall, Melissa J., and Amanda Rutherford. 2016. "Voting Rights for Whom? Examining the Effects of the Voting Rights Act on Latino Political Incorporation.” American Journal of Political Science 60(3): 590-606.

McCubbins, Matthew D., and Thomas Schwartz. 1984. "Congressional Oversight Overlooked: Police Patrols and Fire Alarms.” American Journal of Political Science 28(1): 16579.

Mills, Russell W., Nicole Kalaf-Hughes, and Jason A. MacDonald. 2016. "Agency Policy Preferences, Congressional LetterMarking and the Allocation of Distributive Policy Benefits." Journal of Public Policy 36(4): 547-71.

Minta, Michael D. 2009. "Legislative Oversight and the Substantive Representation of Black and Latino Interests in Legislative Oversight and the Substantive Representation of Black and Latino Interests in Congress." Legislative Studies Quarterly 34(2): 193-218.

Minta, Michael D. 2011. Oversight: Representing the Interests of Blacks and Latinos in Congress. Princeton, NJ: Princeton University Press.

Ritchie, Melinda N. 2018. "Backchannel Representation: A Study of the Strategic Communication of Senators with the U.S. Department of Labor." The Journal of Politics 80(1): 240-253.

Ritchie, Melinda N., and Hye Young You. 2019. "Legislators as Lobbyists.” Legislative Studies Quarterly 44(1): 65-95.

Salisbury, Robert H., and Kenneth A. Shepsle. 1981. "U.S. Congressman as Enterprise." Legislative Studies Quarterly 6(4): 559-76.

Sen, Maya, and Omar Wasow. 2016. "Race as a'Bundle of Sticks': Designs That Estimate Effects of Seemingly Immutable Characteristics." Annual Review of Political Science 16: 499-522.

Swain, Carol. 1993. Black Faces, Black Interests: The Representation of African Americans in Congress. Cambridge, MA: Harvard University Press.

Swers, Michele L. 1998. "Are Women More Likely to Vote for Women's Issue Bills Than Their Male Counterparts?” Legislative Studies Quarterly 23(3): 435-48. 
Swers, Michele L. 2002. The Difference Women Make: The Policy Impact of Women in Congress. Chicago: University of Chicago Press.

Swers, Michele L. 2013. Women in the Club: Gender and Policy Making in the Senate. Chicago: University of Chicago Press.

Tate, Katherine. 2003. Black Faces in the Mirror: African Americans and Their Representatives in the U.S. Congress. Princeton, NJ: Princeton University Press.

Tausanovitch, Chris, and Christopher Warshaw. 2013. "Measuring Constituent Policy Preferences in Congress, State Legislatures, and Cities." The Journal of Politics 75(2): 330-42.

Welch, Susan. 1985. "Are Women More Liberal Than Men in the U.S. Congress?” Legislative Studies Quarterly 10(1): 125-34.

Wolbrecht, Christina. 2000. The Politics of Women's Rights: Parties, Positions, and Change. Princeton, NJ: Princeton University Press.
Wolbrecht, Christina. 2002. “Explaining Women's Rights Realignment: Convention Delegates, 1972-1992.” Political Behavior 24(3): 237-82.

\section{Supporting Information}

Additional supporting information may be found online in the Supporting Information section at the end of the article.

Appendix A: Data Collection and Coding Procedure Appendix B: Additional Results

Appendix C: Detecting Meaningful Differences 